\title{
Improving the delivered power quality from WECS to the grid based on PMSG control model
}

\author{
Shimaa A. Hussien', M. A. Deab ${ }^{2}$, N. S. Hosny ${ }^{3}$ \\ ${ }^{1}$ Electrical Department Faculty of Engineering, Princess Nourah bint Abdulrahman University, Saudi Arabia \\ ${ }^{1}$ Electrical Power and Control Department, Pyramids Higher Institute for Engineering and Technology, Egypt \\ ${ }^{2}$ Power and Energy Department New Cairo Technological University, Egypt \\ ${ }^{3}$ Electrical Power and Control Department Pyramids Higher Institute for Engineering and Technology, Egypt
}

\begin{tabular}{l}
\hline \hline Article Info \\
\hline Article history: \\
Received Mar 23, 2020 \\
Revised Jun 7, 2020 \\
Accepted Jun 17, 2020 \\
\hline Keywords: \\
Permanent magnet synchronous \\
generator (PMSG) \\
Wind energy conversion system \\
(WECS) \\
Mine blast algorithm (MBA) \\
Harmony search optimization \\
technique (HSO) \\
PSIM \\
MATLAB/Simulink
\end{tabular}

\section{Corresponding Author:}

\section{N. S. Hosny,}

Electrical Power and Control Department,

Pyramids Higher Institute for Engineering and Technology,

Giza, Egypt.

Email: nesreen.samir@gmail.com

\begin{abstract}
Renewable energy has become one of the most energy resources nowadays, especially, wind energy. It is important to implement more analysis and develop new control algorithms due to the rapid changes in the wind generators size and the power electronics development in wind energy applications. This paper proposes a grid-connected wind energy conversion system (WECS) control scheme using permanent magnet synchronous generator (PMSG). The model works to improve the delivered power quality and maximize its value. The system contained one controller on the grid side converter (GSC) and two simulation packages used to simulate this model, which were PSIM software package for simulating power circuit and power electronics converters, and MATLAB software package for simulating the controller on Simulink. It employed a meta-heuristic technique to fulfil this target effectively. Mine-blast algorithm (MBA) and harmony search optimization technique (HSO) were applied to the proposed method to get the best controller coefficient to ensure maximum power to the grid and minimize the overshoot and the steady state error for the different control signals. The comparison between the results of the MBA and the HSO showed that the MBA gave better results with the proposed system.
\end{abstract}

Copyright $\odot 2020$ Institute of Advanced Engineering and Science. All rights reserved.

\section{INTRODUCTION}

The worldwide demand for energy is increasing gradually. Renewable energy could be a useful power source to reduce the fossil fuel consumption and its corresponding pollution. Wind energy is a powerful renewable source, which could be used in many areas. Various types of wind generators have been used in WECS, for example, double-fed induction generator (DFIG), the wound rotor synchronous generator, squirrel-cage induction generator, high-temperature-superconducting synchronous generator, and permanent magnet synchronous generator (PMSG). To extract the maximum power from systems with variable speed wind turbines (VSWT), different power converters and control topologies could be used.

The advantages of VSWT compared with fixed speed generators are that the extracted energy could be increased, operating at maximum power point is possible, and the efficiency along with the power quality could be improved [1]. Using a direct drive PMSG could improve meaningfully the dependability of VSWT. Although many types of generators could be used in WECS, the PMSG plays a chief role in the market [2, 3]. Modelling and control of this system has been implemented for grid-tie [4-7] or stand-alone system [8]. 
Also, proportional resonant controllers were used to help in the elimination of steady-state error and enhance the performance of the reference tracking of the converter [9].

The advantages of PMSG are the possibility of multi-pole design that ensures, gearless WECS construction possibility, operating with slow speed, and free maintenance operation as no brushes exist. The significant disadvantage of PMSG is that the output voltage depends on the speed of rotation. Many applications and control systems were applied on this system [10-19]. Also, many algorithms were used to such problems [20-25]. It is possible that the minimum voltage and maximum voltage difference could reach four times in the applications of VSWT [26]. This disadvantage could be simply overcome with the help of a suitable interfacing converter.

Optimum power/torque tracking strategies are commonly used as they help to achieve optimum wind energy extraction. They use the velocity of the wind in order to determine the required shaft speed to vary the speed of the generator. However, anemometer based control strategy decreases the system reliability and increases cost. This control strategy may not suit or may be with high cost for a small scale wind turbine system.

In this paper, a proposed system was introduced containing a fully controlled inverter. MBA optimization technique [27] was implemented to get the maximum power under a certain grid voltage. A comparison of the proposed system results with the results of the same system using HSO technique [28] was carried out to identify the best technique. The comparative analysis of the results showed that the MBA was the better one.

Section 2 introduces the materials and methods including the mathematical model and the optimization algorithms. The results and the discussion are presented in section 3 . Section 4 will introduce the conclusions of the work.

\section{RESEARCH METHOD}

The system would be built on PSIM software to simulate the response of WECS. The controller and the optimization algorithm would be simulated with Matlab/Simulink [29]. The model containes a directdriven wind turbine without gearbox, a PMSG, an uncontrolled rectifier, a DC link, a fully controlled inverter, and a transmission line to the grid as shown in Figure 1.

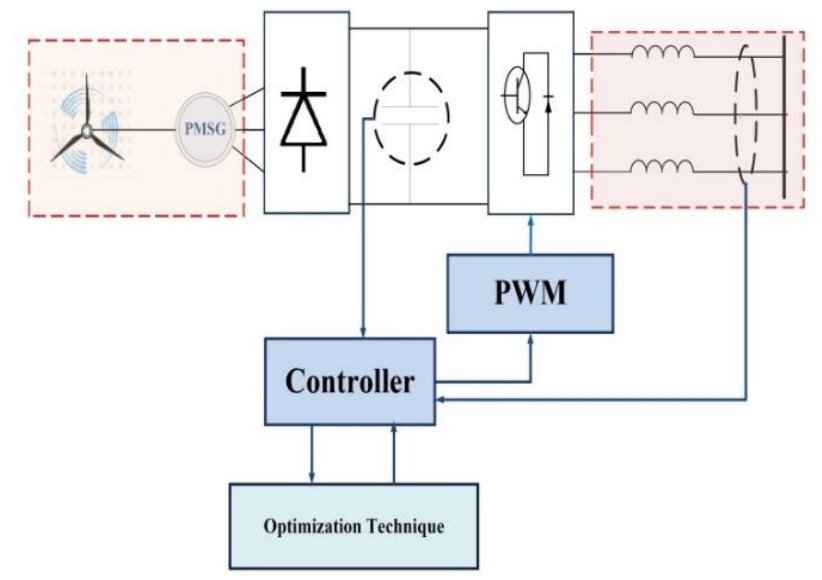

Figure 1. System block diagram

Two power converters used in the system are uncontrolled three-phase rectifier, used in machine side for the conversion of the PMSG output to DC power, and a fully controlled three-phase inverter, used for the DC to AC power conversion that could be transmitted to the grid. A PI controller would be used to generate the inverter switches firing angles using pulse width modulation (PWM). The controller gains could be determined using a meta-heuristic optimization technique to get the optimum wave form delivered to the grid as shown in Figure 2. Furthuremore, only a proper estimate of the filter resistance and inductance would be required for the design.

The controller performance would be evaluated by the simulation results analysis for various quantities with two different optimization techniques -MBA and HSO. The quantities under consideration are the power and the average power delivered to the grid $\left(\mathrm{P}_{\mathrm{o}}\right.$, Avg. $\left.\mathrm{P}_{\mathrm{o}}\right)$, the wind turbine speed and the mechanical torque $\left(\mathrm{N}_{\mathrm{m}}, \mathrm{T}_{\mathrm{em}}\right)$, the three-phase generator terminal current, the three-phase grid side current, and the dc-link voltage. These two optimization techniques results would be compared to identify 
the best one for maximum power extraction delivered from WECS. Figure 3 represents the relation between the generator speed and the extracted power at different wind speed. It indicates that the maximum power could be captured from the wind turbines only if they are of a variable speed type.

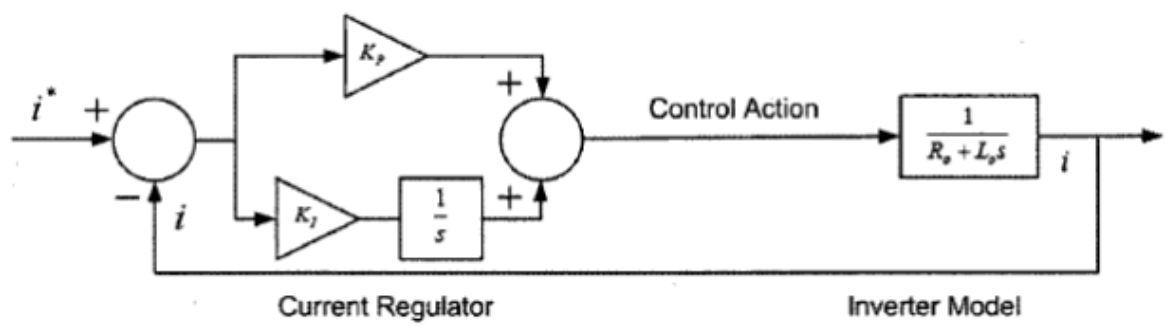

Figure 2. System controller

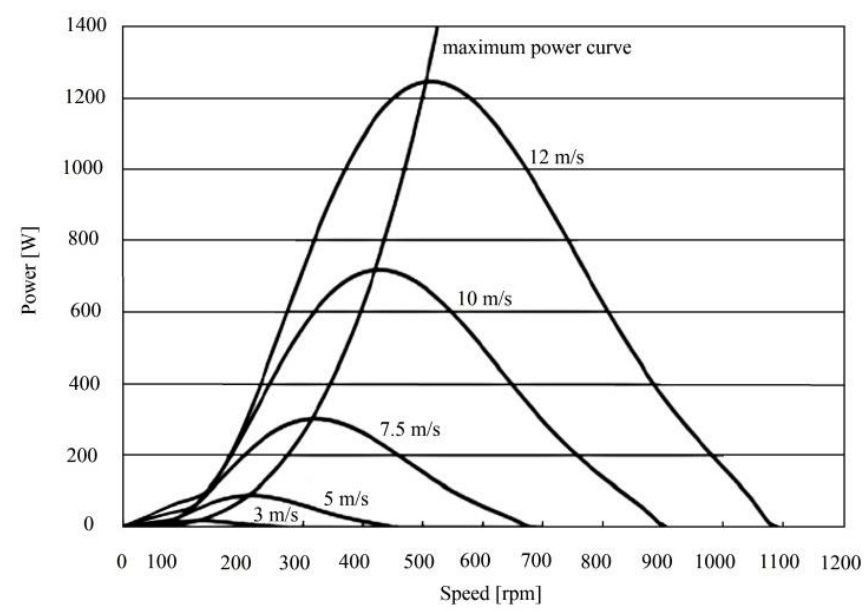

Figure 3. Speed-power curve

\subsection{Mathematical model}

Wind turbine power is computed as [14]:

$$
P_{t}=\frac{1}{4} \rho A C_{p} v_{w}^{3}
$$

where $P_{t}$ is the power of the turbine, $\rho$ is the density of the air, A is the swept area of the turbine, CP is the performance coefficient and $v_{w}$ is the speed value of the wind.

Dynamic model of the PMSG could be introduced as:

$$
\begin{aligned}
& V_{d}=R_{s} i_{d}+\lambda_{d}-\omega_{e} \psi_{q} \\
& V_{q}=R_{s} i_{q}+\lambda_{q}-\omega_{e} \psi_{d}
\end{aligned}
$$

where the d-q components of the stator voltage are $V_{d}$ and $V_{q}$, and the d-q components of the stator current are $i_{d}$ and $i_{q} . \psi_{d}$ and $\psi_{q}$ are the $\mathrm{d}-\mathrm{q}$ components of the stator flux linkage. $R_{s}$ is the resistance of the stator. The electric angular rotor speed is $\omega_{e}(\mathrm{rad} / \mathrm{s})$.

The $\mathrm{d}-\mathrm{q}$ components of the stator flux linkage could be expressed as:

$$
\begin{aligned}
& \psi_{d}=L_{d} i_{d}+\psi_{P m} \\
& \psi_{q}=L_{q} i_{q}
\end{aligned}
$$

where $L_{d}$ is the d-axis inductance and $L_{q}$ is q-axis inductance of the stator. $\psi_{P m}$ the permanent magnet flux linkage. 


\subsection{MBA technique}

Observation of the explosion a mine bomb was the main purpose of constructing the MBA, where thrown shrapnel pieces would collide with possible mine bombs in an explosion area causing further explosion. The discovery of the location of the optimum point of the most explosive bomb is the objective [27]. Mine bombs planted under the ground are with versatile sizes or power of explosion. Any bomb would spread many shrapnel pieces when it is exploded as shown in Figure 4. Each piece of shrapnel would cause victims. If the number of victims per piece in an area is high, so existence of other mines in this area might be taken into consideration. These mines might be with a higher power of explosion. There are certain directions and distances for each shrapnel piece would collide with other mine bombs, which may be the reason of the explosion of others. The discovery of the most explosive mine could be recognized. The objective function fitness at the mine bomb's location would be considered a mine bomb explosion by the victims.

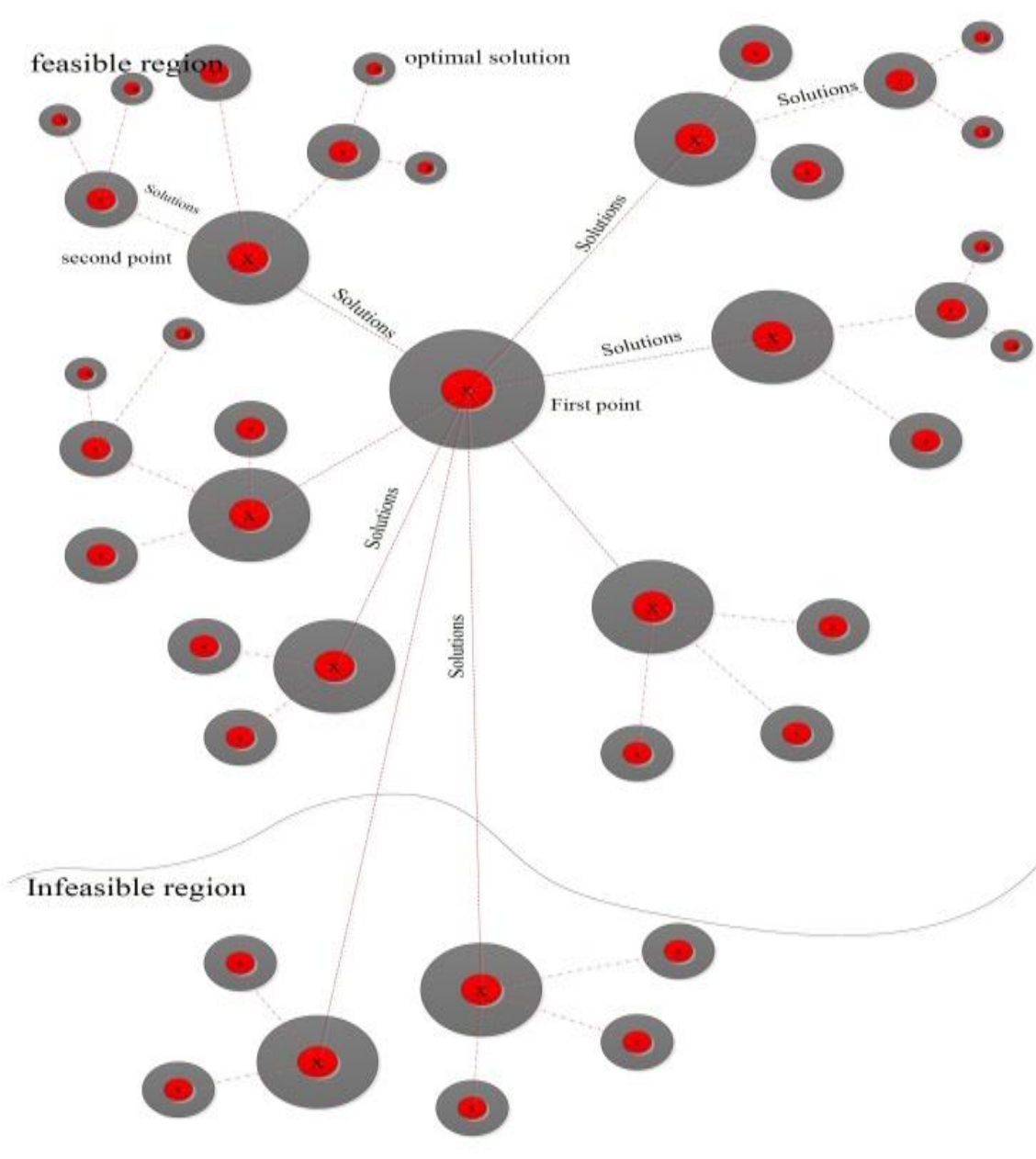

Figure 4. Mine blast algorithm

The suggested MBA technique starts initially with a point(s) named the first shot point(s). This point could be defined as $x_{0}^{f}$, where $\mathrm{f}$ is a parameter defined by the user, which equals the number of first shot point(s), ( $f=1,2,3, \ldots$. . The first shot point(s) location(s) might be assumed randomly by the algorithm using the problem upper and lower boundaries. MBA, similar to other meta-heuristic techniques, requires initially a population of individuals. Using the first shot explosion, MBA could generate a population to produce shrapnel pieces (individuals). $N_{\text {pop }}$ is the initial population and its value is according to shrapnel pieces value $N_{s}$.

A small randomly generated value would be created by the first shot point to give the value:

$$
x_{0}=L B+\operatorname{rand} \times(U B-L B)
$$


Here $x_{0}$ is the initial first shot point, LB is the lower boundary and UB is the upper boundary of the problem. The term (rand) is to indicate that the distribution is uniform between [0, 1] randomly. Using many first shot points would increase the initial populations and number of functions to be evaluated.

Assume $x$ to be the mine bomb current location and expressed as:

$$
x=\left\{x_{m}\right\}, \quad m=1,2,3,4, \ldots \ldots \ldots, N_{d}
$$

The variable $N_{d}$ equals the search space dimension, which $N_{s}$ shrapnel pieces of an explosion would cause another bomb to explode at $x_{n+1}$ location:

$$
x_{n+1}^{f}=x_{e(n+1)}^{f}+\exp \left(-\sqrt{\frac{m_{n+1}^{f}}{d_{n+1}^{f}}}\right) x_{n}^{f}, n=0,1,2
$$

where $x_{e(n+1)}^{f}$ is the exploding mine bomb location, which was collided by shrapnel, $d_{n+1}^{f}$ is the distance, and $m_{n+1}^{f}$ is the thrown shrapnel pieces slope (direction) in each iteration.

The location $x_{e(n+1)}^{f}$ is expressed as:

$$
x_{e(n+1)}^{f}=d_{n}^{f} \times \text { rand } \times \cos \cos (\theta), \quad n=0,1,2,3
$$

$(\theta)$ is the shrapnel pieces angle, which could be obtained from $\theta=\frac{360}{N_{s}}$ in constant value.

In (9) is used for real world simulation of mine bomb's explosion. Each individual (shrapnel piece) has variable distances with definite directions from the explosion point. The best optimum point could be obtained by exploring - at each iteration- the domain space in $360^{\circ}$, which is specified by $\theta$ and $d_{n}^{f}$. The value of $\theta$ would be set to $\frac{360}{N_{S}}$ to carry out a uniform search. By this procedure, accumulation of individuals in a specific region might be prevented.

In (8), the obtained blast point progress is done using the exponential term by manipulating the information from previous solutions $\left(x_{n}^{f}\right)$. The shrapnel pieces distance $\left(d_{n+1}^{f}\right)$ and direction $\left(m_{n+1}^{f}\right)$ are:

$$
\begin{aligned}
& d_{n+1}^{f}=\sqrt{\left(x_{n+1}^{f}-d x_{n}^{f}\right)^{2}+\left(F_{n+1}^{f}-F_{n}^{f}\right)^{2}}, \quad n=0,1, \\
& m_{n+1}^{f}=\frac{F_{n+1}^{f}-F_{n}^{f}}{F_{n+1}^{f}-F_{n}^{f}} \quad, \quad n=0,1,2,3,
\end{aligned}
$$

where $(\mathrm{F})$ is the function value of the $(x)$. The initial distance would be calculated by $d_{0}=(U B-L B)$ in each dimension used. To search optimum solution, the initial distance would be proposed within a range ( $L B$ $<d_{0}<U B$ ), which is computed by multiplying a randomly generated number and the initial distance. Searching factor $(\mu)$ is used to conduct design space exploration at smaller and larger distances. This constant would be compared with an iteration number index (k) to begin the exploration process if it is larger than $\mathrm{k}$.

Exploration of the solution space could be indicated as:

$$
\begin{aligned}
& d_{n+1}^{f}=d_{n}^{f} \times(|\operatorname{rand} n|)^{2}, \quad n=0,1,2, \ldots \\
& d_{e(n+1)}^{f}=d_{n}^{f} \times \cos \cos (\theta), \quad n=0,1,2, \ldots .
\end{aligned}
$$

In (13) modifies each shrapnel pieces' distance. $(\mid \text { randn } \mid)^{2}$ Provides better exploration of the ability to search. Hence, they shift closer to an optimum point quickly during a small number of iterations. The larger the $(\mu)$ value, the more remote regions to explore as the $(\mu)$ value is used to assign the exploration intensity. The ability of the search would be increased globally using this methodology; gradual reduction in the distance of shrapnel pieces would allow better probable search for the bomb's location. The decrease in $d_{0}{ }^{f}$ is given as:

$$
d_{n}^{f}=\frac{d_{n-1}^{f}}{\exp \left(\frac{k}{\alpha}\right)} \quad n=1,2,3,
$$


where $\mathrm{k}$ and $\alpha$ are the iteration number index and decrease constant, respectively. The constsnt $(\alpha)$, which is a user parameter, depends on the problem difficulty. The effect of $(\alpha)$ is to decrease the distance of each shrapnel pieces against as introduced in (14). Therefore, the problem interval is totally searched between lower and upper boundaries. To find the optimum solution globally, the shrapnel distance value would be roughly set to zero in the final iteration. Two processes could be implemented for searching the solution domain: the exploration procedure and exploitation procedure. Whole search towards the optimal solution is got by the difference between these two processes, which in what way they affect specifically. $(\mu)$ is used as an exploration factor to signify the value of the first iterations. Later, if $(\mu)$ is set to a certain number of iterations, then for this iterations number the algorithm would calculate the distance and the explosion location as illustrated in (13) and (14), respectively. For the exploitation process, the algorithm is interested on the optimum point. Exactly, considering the process of exploitation, it would determine the exploded mine bomb location, shrapnel pieces' direction and distance, respectively. The algorithm would converge to the global optimum solution as illustrated in (9), (10), and (11), then in (14) reduces adaptively. It converges to the objective function optimal solution of shrapnel pieces' distance. The flow chart in Figure 5 will illustrate the steps of algorithm.

\subsection{HSO technique}

A meta-heuristic algorithm called HSO, it was stimulated by the basic principles of the musicians' invention of searching for the harmony with a perfect state of harmony musical process in order to obtain the best solution in an optimization process with the harmony in music analogously [28]. To get the best tune, a musician plays different segments of notes of changed musical instrument and find the best combination of frequency in music invention progression. In the same way, in the HSO algorithm, to minimize or maximize the objective function, selecte the best combination of existing solutions. Definitely, HSO was stimulated by managing musician's equipment, who rapidly improve their individual, resulting in a beautiful harmony. HSO has mainly five steps:

- Initialize the algorithm parameters

In steps 1 , specify the problem as follows:

Minimize $\mathrm{f}(\mathrm{x})$ as an objective function

Subject to $x_{j} \in X_{j}, j=1,2,3, \ldots \ldots n$

where, $x_{j}$ is the set of each decision variable; $x_{j}: n$ is the number of decision variables, $x_{i}^{L} \leq X_{j} \leq x_{i}^{U}$ is the set of the lower and upper bounds of each decision variable. Here, the paremeters are specified and the harmony memory (HM) is the memory location where the solution vectors are stored.

- Number of solution vectors in the harmony memory (HM)

- Harmony memory considering rate (HMCR)

- Pitch adjusting rate (PAR)

- Number of inventions (NI), or stopping criterion;

Here, adjusts the HM matrix to complete with a lot of solution vectors - created randomly - as the HMS.

$$
H M=\left[\begin{array}{cccc}
x_{1}^{1} & x_{2}^{1} & \ldots & x_{n}^{1} \\
x_{1}^{2} & x_{2}^{2} & \ldots . & x_{n}^{2} \\
\vdots & \vdots & \ldots . & \vdots \\
x_{1}^{H M S} & x_{2}^{H M S} & \ldots . & x_{n}^{H M S}
\end{array}\right]
$$

- Improve a new harmony

Novel vector is created depending on pitch adjustment, memory consideration, and random selection, a new harmony is called improvisation would be generated. The first decision $x_{1}^{1}$ could b e chosen from the range $x_{1}^{1}-x_{1}^{H M S}$, and the same manner for the rest of decisions choice. HMCR $\epsilon[0,1]$, is the rate of selecting one value from the stored historic values in the HM. $(1-\mathrm{MCR})$ is the rate of randomly choosing one value from the possible range of values.

$$
x_{j}^{\prime} \leftarrow\left\{\begin{array}{l}
x_{j}^{\prime} \in\left\{x_{j}^{1}, x_{j}^{2}, \ldots \ldots, x_{j}^{1 H M S}\right. \text { with probabilty HCMR } \\
x_{j}^{\prime} \in X_{j} \quad \text { with probabilty }(1-H C M R)
\end{array}\right.
$$

This process uses the PAR $\in[0,1]$ parameter, which is the rate of pitch adjustment: 


$$
x_{j}^{\prime} \leftarrow\left\{\begin{array}{lr}
\text { Adjusting pitch } & \text { with probabilty } P A R \\
\text { Doing Nothing } & \text { with probabilty }(1-P A R)
\end{array}\right.
$$

The value of $(1-P A R)$ sets the rate of doing nothing. If the pitch adjustment decision for $x_{j}^{\prime}$ is YES, $x_{j}^{\prime}$ is replaced as:

$$
x_{j}^{\prime} \leftarrow x_{j}^{\prime} \pm \text { rand } \times b w
$$

where, $b w$ is a random distance band width. rand is a random number between 0 and 1 .

- Update memory of harmony

The objective function $f\left(x_{j}^{\prime}\right)$ value is calculated when the novel HSO vector is better than the worst harmony in the HM. The HM would include the new harmony, with the omittion to the current worst one.

- Checked the stopping criterion

If inventions maximum number is reached, the stopping criterion is finished. Else, improve and update the memory is repeated. Finally, the best HM vector is designated and is well-thought-out as best solution. Figure 6 illustrated the flow chart of the harmony search algorithm.

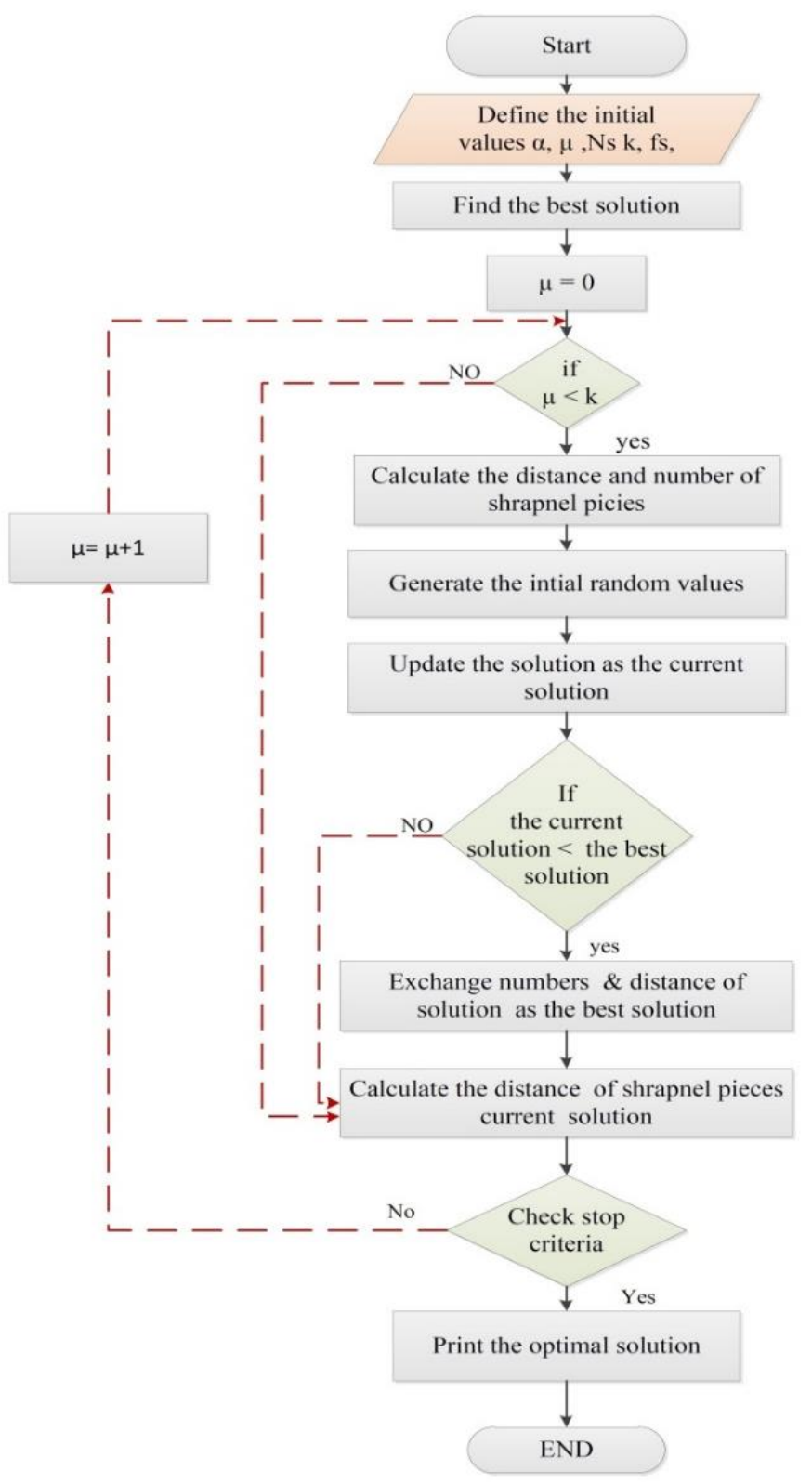

Figure 5. Flow chart of mine blast algorithm 


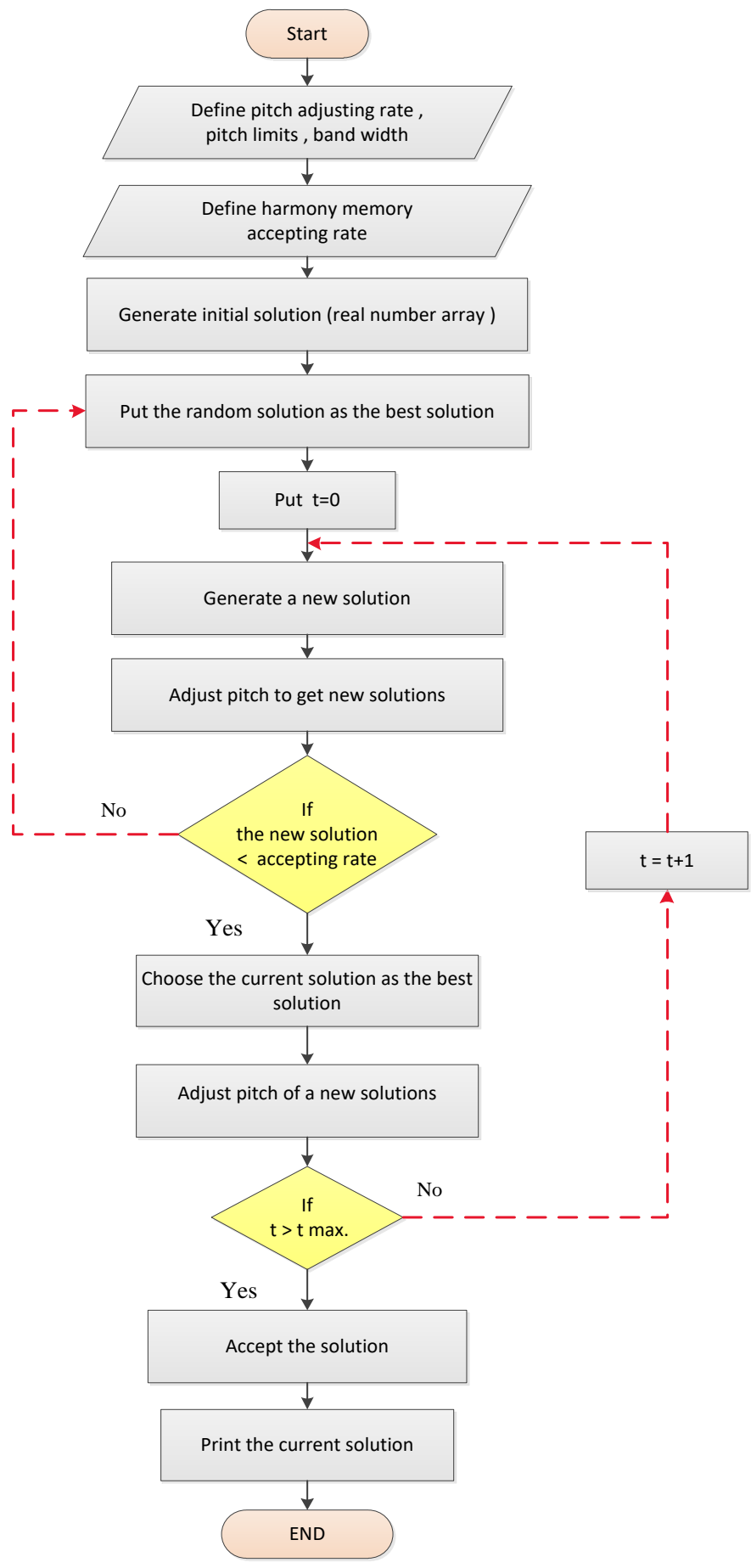

Figure 6. Flow chart of harmony search algorithm

\section{RESULTS AND DISCUSSION}

Simulation programs have been used to simulate the system; PSIM/Simulink contained the WECS power circuit, and Matlab/Simulink had the control system and optimization technique. The wind turbine characteristics are shown in Table 1, and PMSG parameters are in Table 2 [30]. To get the best linkage between the Simulink and PSIM simulation, the sampling time for the simulation was taken $5 \mu$, the total simulation time was taken $0.2 \mathrm{~s}$, and rung kutta fixed step solver were used. Also, a step change from $12 \mathrm{~m} / \mathrm{s}$ to $18 \mathrm{~m} / \mathrm{s}$ in wind speed was implemented on the system to study the response. The two optimization techniques were implemented on the system to find the controller parameters, which would lead to the goal of delivered power optimization. The settings for the MBA and HSO are shown in Tables 3 and 4. 
Table 1. Wind turbine model parameters

\begin{tabular}{ll}
\hline Parameter & Value \\
\hline Nominal output power & $19 \mathrm{kw}$ \\
Base wind speed & $12 \mathrm{~m} / \mathrm{s}$ \\
Base rotational speed & $190 \mathrm{rpm}$ \\
Moment of inertia & $1 \mathrm{~m}$ \\
Pitch angle of blade & $0 \circ$ \\
\hline
\end{tabular}

Table 3. Control parameters of MBA

\begin{tabular}{cc}
\hline Parameter & Value \\
\hline No. of shrapnel pieces & 50 \\
Reduction factor & 1.5 \\
No. of function evaluations & 10,000 \\
No. of iterations & 100 \\
\hline
\end{tabular}

Table 2. PMSG model parameters

\begin{tabular}{ll}
\hline Parameter & Value \\
\hline$R_{s}$ (stator resistance) & $1 \mathrm{~m}$ \\
$L_{d}$ (inductance of d-axis) & $1 \mathrm{~m}$ \\
$L_{q}$ (inductance of q-axis) & $1 \mathrm{~m}$ \\
$\mathrm{P}$ (number of poles) & 30 \\
Moment of inertia & $100 \mathrm{~m}$ \\
\hline
\end{tabular}

Table 4. Control parameters of HSO

\begin{tabular}{ll}
\hline Parameter & Value \\
\hline Harmony memory (HM) & 50 \\
Harmony memory considering Rate (HMCR) & 0.9 \\
Pitch adjusting rate (PAR) & $0.1-0.9$ \\
Band width & $0.001-1$ \\
No. of iterations (NI) & 200 \\
\hline
\end{tabular}

Figure 7 (see in appendix) presents the simulation results for the system using the MBA with $12 \mathrm{~m} / \mathrm{s}$ speed. When the speed increased with $6 \mathrm{~m} / \mathrm{s}$, the system showed good response with that change. The simulation results for the system with HSO technique are shown in Figure 8 (see in appendix), considering the same conditions. The system quantities - power and the average power delivered to the grid $\left(\mathrm{P}_{\mathrm{o}}\right.$ Avg. $\left.\mathrm{P}_{\mathrm{o}}\right)$, the wind turbine speed and the mechanical torque $\left(\mathrm{N}_{\mathrm{m}}, \mathrm{T}_{\mathrm{em}}\right)$, the three-phase generator terminal current, the three-phase grid side current, and the dc-link voltage- were evaluated. Figure 9 illustrates the difference between the power curves with MBA and HSO techniques. The MBA response has less max positive and negative over shoot and reaches the steady state fast than HSO technique as well. Figure 10 depicts the DC link voltage with MBA and HSO techniques [31].

Comparing between the two systems responses, it could be noticed that the main change appeared in the DC link voltage curve and the power delivered curve. Also, the system response oscillated with HSO technique and had a max overshoot of $635 \mathrm{~V}$. The MBA technique response was better since it had a $610 \mathrm{~V}$ max overshoot and there was no oscillation. From those results, it might be suggested that the use of the proposed technique with the impelementaion of the MBA would be able to give better results.

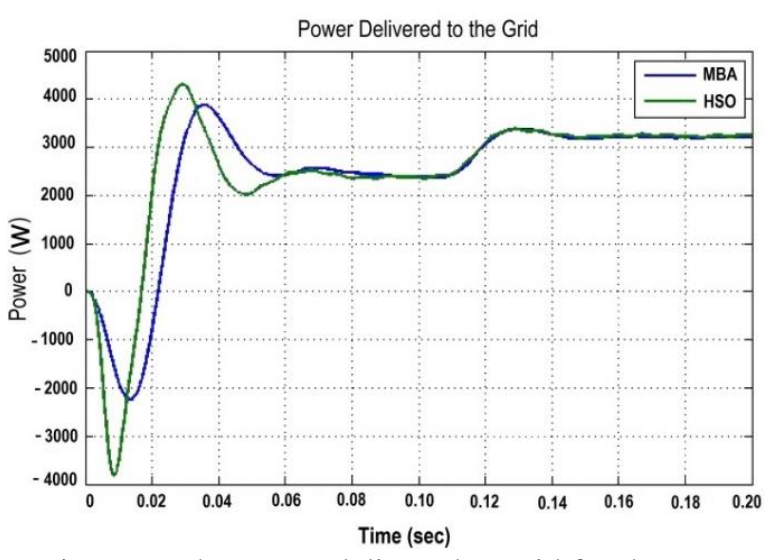

Figure 9. The power delivered to grid for the two techniques

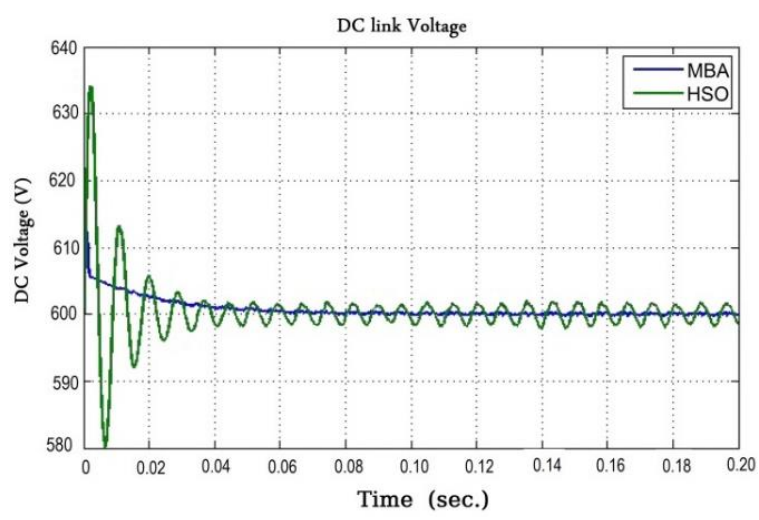

Figure 10. The DC link voltage for the two techniques

\section{CONCLUSION}

A PMSG used in WECS connected to grid has been simulated. Matlab/Simulink software package was used to simulate the controller and optimization technique, and the PSIM software package was used to simulate the power circuits and power converter. The proposed system contained a direct-driven turbine without gearbox and an uncontrolled generator side converter that was used to covert the output of the generator to a DC power. A fully controlled inverter was used to covert the DC power in the DC link to AC power that would be delivered to the grid. A PI controller was used to generate the inverter switches firing angles using PWM, which parameters could be modified to get the optimum wave form delivered to the grid. Two optimization techniques-MBA and HSO-were implemented on the controller and their results were compared. The MBA technique results were better as they had less maximum overshoot and less 
settling time than the results of the HSO technique. In conclusion, it could be recommended to use the MBA technique with the proposed system to get the best controller parameters that get the best wave form for the power delivered to the grid.

\section{APPENDIX}

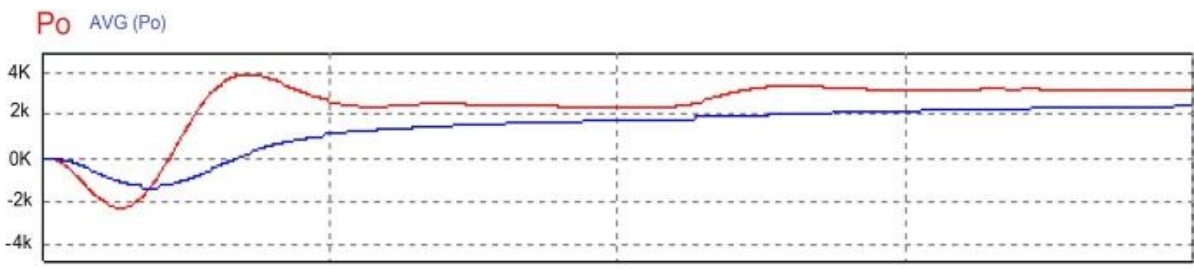

(a)

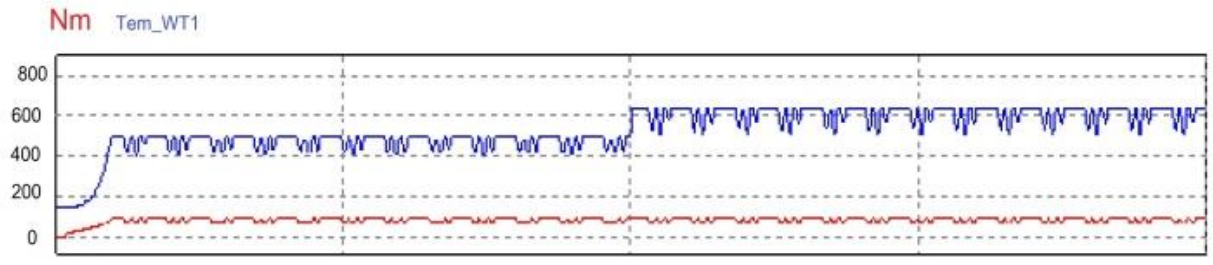

(b)

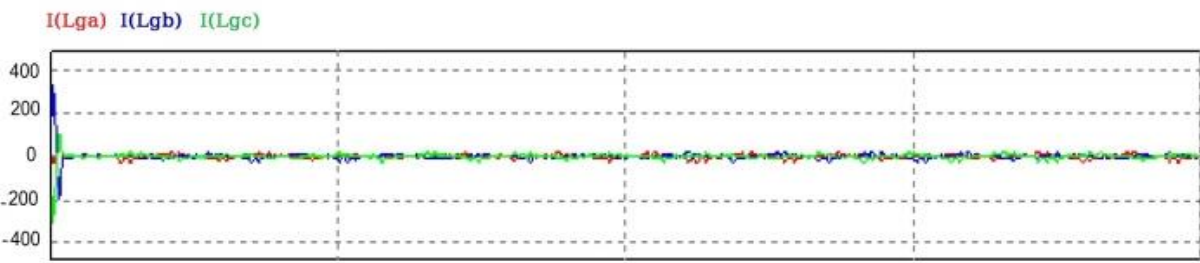

(c)

I(Lga) $I(\operatorname{Lgb}) \quad I(\operatorname{Lgc})$

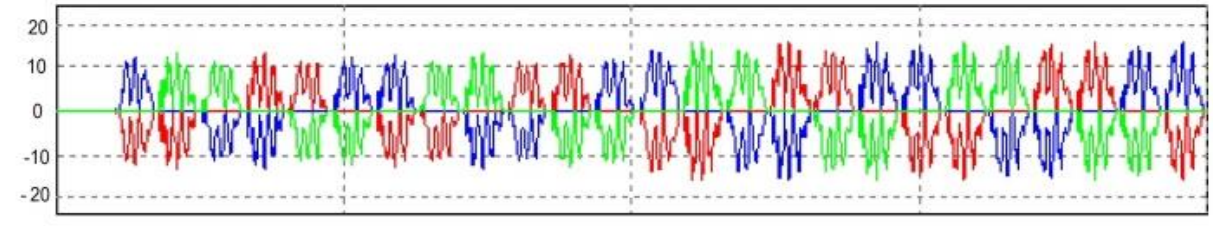

(d)

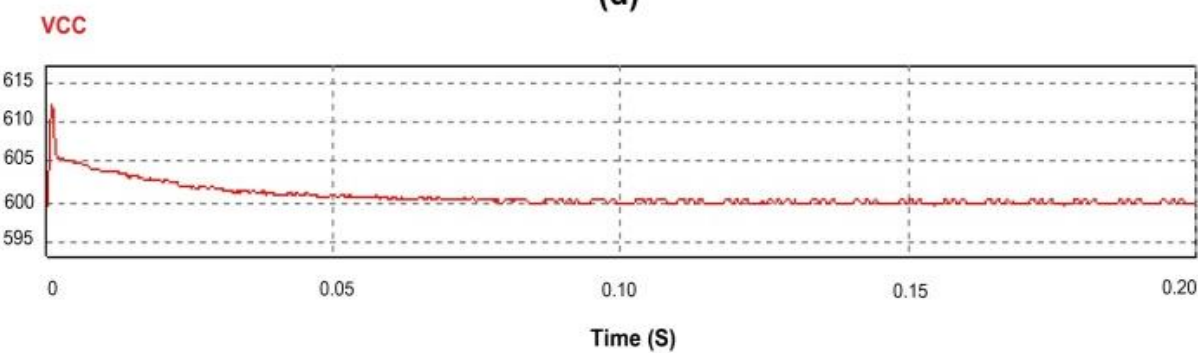

(e)

Figure 7. MBA technique simulation results (a) The power delivered to the grid and its average,

(b) The turbine speed and mechanical torque, (c) Three-Phase generator current,

(d) Three-Phase grid side current and (e) DC voltage of DC link 


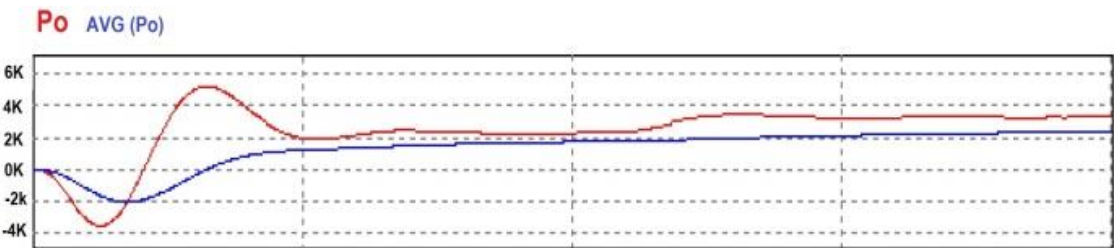

(a)

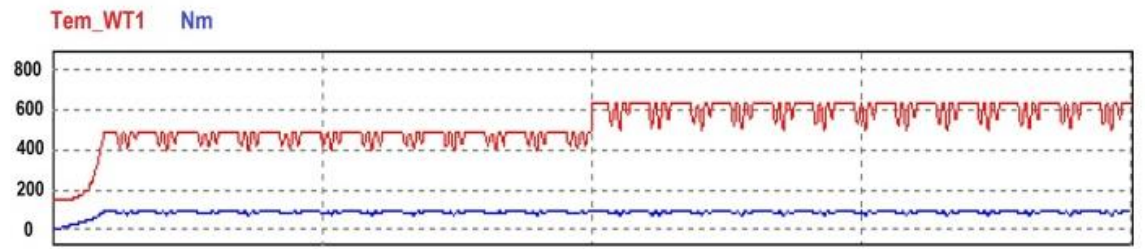

(b)

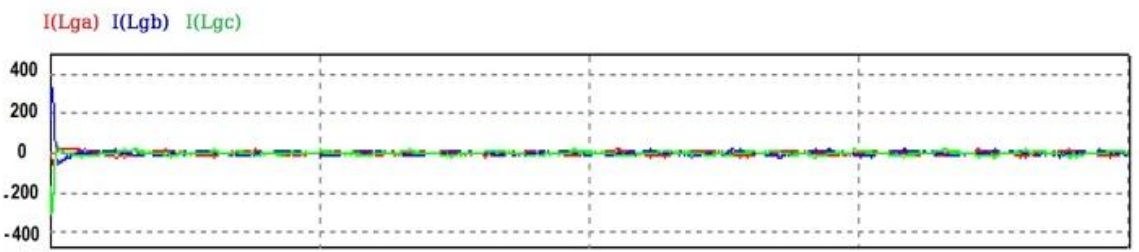

(c)

I(Lga) I(Lgb) I(Lgc)

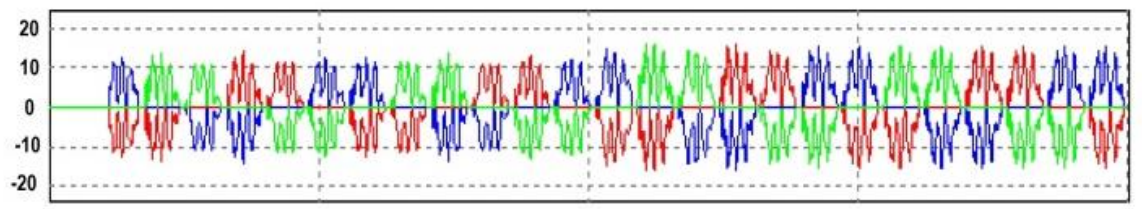

(d)

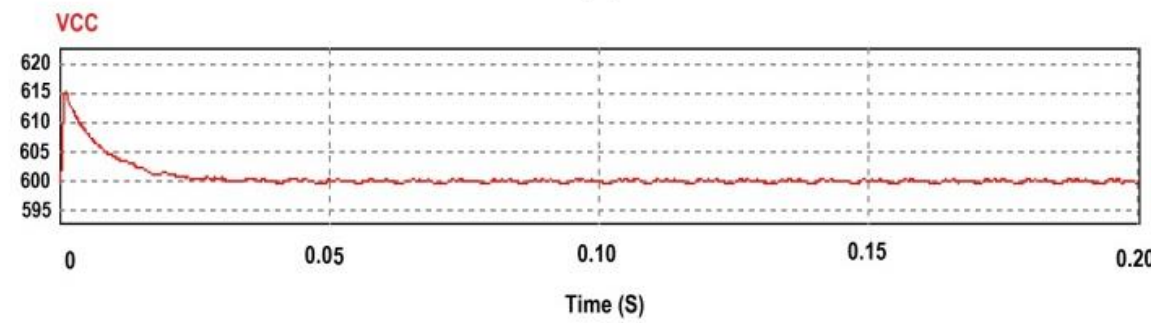

(e)

Figure 8. HSO technique simulation results, (a) The power delivered to the grid and its average,

(b) The turbine speed and mechanical torque, (c) Three-Phase generator current;

(d) Three-Phase grid side current, (e) DC Voltage of DC link

\section{ACKNOWLEDGEMENTS}

This research was funded by the Deanship of Scientific Research at Princess Nourah bint Abdulrahman University through the Fast-track Research Funding Program.

\section{REFERENCES}

[1] M. E. Haque, M. Negnevitsky, K. M. Muttaqi, "A novel control strategy for a variable speed wind turbine with a permanent magnet synchronous generato," IEEE Transactions on Industry Applications, vol. 46, no. 1, pp. 331-339, 2010.

[2] B. Beltran, T. Ahmed Ali, and M. E. H. Benbouzid, "High-order sliding-mode control of variable speed wind turbines," IEEE Trans. Ind. Electron., vol. 56, no. 9, pp. 3314-3321, 2009. 
[3] A. Z. Mohamed, M. N. Eskander, and F. A. Ghali, "Fuzzy logic control based maximum power tracking of wind energy system," Renew. Energy, vol. 23, no. 2, pp. 235-245, 2001.

[4] Youssef, A., Mohamed, E., Ali, A., "Model Predictive Control for Grid-Tie Wind Energy Conversion System Based PMS," Proc. Int. Conf. on Innovative Trends in computer Engineering, 2018.

[5] M. A. Ahmed, et al.," Dynamic modelling of grid-connected permanent magnet synchronous generator wind turbine: rectifier dynamics and control design," Journal of Engineering, vol. no. 18, pp. 5202-5207, 2019.

[6] X. Wang, Z. Xie and Y, Chang, "Control of PMSG-Based Wind Turbine with Virtual Inertia," 14th IEEE Conference on Industrial Electronics and Applications (ICIEA), pp. 1302-1306, 2019.

[7] Y. Cui, P. Zeng and C. Cui, "Pitch control strategy of permanent magnet synchronous wind turbine generator in response to cluster auto generation control command," IEEE Innovative Smart Grid Technologies-Asia, pp. 4042-4047, 2019.

[8] S. Sahu, G. Panda and S. P. Yadav, "Dynamic Modelling and Control of PMSG based Stand-alone Wind Energy Conversion System," Recent Advances on Engineering, Technology and Computational Sciences, pp. 1-6, 2018.

[9] R. Singh, and Y.K. Chauha, "Modeling and control of PMSG based variable speed wind turbine using proportional resonant controller," Int. Journal of Engineering Research and Application, vol. 7, no. 7, pp. 39-48, 2017.

[10] C. M. Hong, C. H. Chen, and C. S. Tu, "Maximum power point tracking-based control algorithm for PMSG wind generation system without mechanical sensors," Energy Convers. Manag., vol. 69, pp. 58-67, 2013.

[11] R. Aissou, et al., "Corrigendum to Robust nonlinear predictive control of permanent magnet synchronous generator turbine using Dspace hardware," International Journal of Hydrogen Energy, vol. 42, no. 5, pp. 21047-01056, 2017.

[12] Y. Errami, et al., "Proposal of a backstepping control strategy for dynamic performance improvement of PMSG Wind Farm with common DC bus," Proc. 2016 Int. Renew. Sustain. Energy Conf. IRSEC, pp. 397-404, 2017.

[13] A. H. Kasem Alaboudy, A. A. Daoud, S. S. Desouky, and A. A. Salem, "Converter controls and flicker tudy of PMSG - based grid connected wind turbines," Ain Shams Eng. J., vol. 4, no. 1, pp. 75-91, 2013.

[14] Y. Errami, M. Ouassaid, and M. Maaroufi, "A performance comparison of a nonlinear and a linear control for grid connected PMSG wind energy conversion system,” Int. J. Electr. Power Energy Syst., vol. 68, pp. 180-194, 2015.

[15] M. Karabacak, H. I. Eskikurt, "Design, modelling and simulation of a new nonlinear and full adaptive backstepping speed tracking controller for uncertain PMSM," Appl. Math. Model., vol. 36, no. 11, pp. 5199-5213, 2012.

[16] M. Chinchilla, S. Arnaltes, and J. C. Burgos, "Control of permanent-magnet generators applied to variablespeedwind-energy systems connected to the grid," IEEE Trans. Energy Convers., vol. 21, no. 1, pp. 130-135, 2006.

[17] M. Makhad, M. Zazi, and A. Loulijat, "Nonlinear control of WECS based on PMSG for optimal power extraction," International Journal of Electrical and Computer Engineering (IJECE), vol. 10, no. 3, pp. 2815-2823, 2020.

[18] Y. Errami, M. Ouassaid, M. Maaroufia, "Control of a PMSG based wind energy generation system for power maximization and grid fault conditions," Energy Procedia, 2013, vol. 42, pp. 220-229, 2013.

[19] D. Vinnikov, L. Bisenieks, and Ilya Galkin, "New Isolated Interface Converter for PMSG Based Variable Speed Wind Turbines," Przeglad Elektrotechniczny (electrical review), 2012.

[20] Qais, M. H., Hasanien, H. M. and Alghuwainem, S., "Enhanced whale optimization algorithm for maximum power point tracking of variable-speed wind generators," Applied Soft Computing, vol. 86, 2020.

[21] Tumari, M. M., et al. , "A modified Grey Wolf Optimizer for improving wind plant energy production," Indonesian Journal of Electrical Engineering and Computer Science (IJEECS), vol. 18, no. 3, pp. 1123-1129, 2020.

[22] Beghdadi, M., Kouzi, K. and Ameur, A., "New design of an optimized synergetic control by Hybrid BFO-PSO for PMSG integrated in wind energy conversion system using variable step HCS fuzzy MPPT," International Conference in Artificial Intelligence in Renewable Energetic Systems, pp. 30-40, 2019.

[23] Md Idris, M. A., Hao, M. R. and Ahmad, M. A., "A Data Driven Approach to Wind Plant Control using MothFlame Optimization (MFO) Algorithm," International Journal on Advanced Science, Engineering and Information Technology, vol. 9, no. 1, pp. 18-23, 2019.

[24] Suid, M. H., et al., "A modified sine cosine algorithm for improving wind plant energy production," Indonesian Journal of Electrical Engineering and Computer Science (IJEECS), vol. 16, no. 1, pp. 101-106, 2019.

[25] Amin, M. N., et al., "Grasshopper optimization algorithm-based PI controller scheme for performance enhancement of a grid-connected wind generator," Journal of Control, Automation and Electrical Systems, vol. 31, no. 2, pp. 393-401, 2020.

[26] V. Yaramasu, et al., "PMSG-Based Wind Energy Conversion Systems: Survey on Power Converters and Controls," IET Electr. Power Appl., 2017.

[27] A. Fathy, "A Reliable Methodology Based on Mine Blast Optimization Algorithm for Optimal Sizing of Hybrid PV-Wind-FC System for Remote Area in Egypt," Renewable Energy, vol. 95, pp. 367-380, 2016.

[28] Tamás Bányai, Péter Veres, "Optimization of Knapsack Problem with Matlab, Based on Harmony Search Algorithm," Advanced Logistic Systems, vol. 7, no. 1, pp. 13-20, 2013.

[29] N. Singh, V. Agrawal, "A survey on power quality improvement converter of PMSG," IET Chennai Fourth International Conference on Sustainable Energy and Intelligent System-K.C.G College of Technology-Chennai, 2013.

[30] A. M. Eltamaly, and H. M. Farh, "Maximum power extraction from wind energy system based on fuzzy logic control," Electric Power Systems Research, vol. 97, no. 144-150, 2013.

[31] I. M. Diaa, N. M. Badra, and M. A. Attia, "Harmony search and nonlinear programming based hybrid approach to enhance power system performance with wind penetration," International Electrical Engineering Journal (IEEJ), vol. 7, pp. 2323-2330, 2016. 